\title{
University Students' Perception of the Pedagogical Use of Podcasts: A Case Study of an Online Information System Course
}

\author{
Hager Khechine ${ }^{1}$, Sawsen Lakhal ${ }^{2} \&$ Daniel Pascot ${ }^{1}$ \\ ${ }^{1}$ Management Information Systems Department, Faculty of Business administration, Laval University, Quebec \\ City, Canada \\ ${ }^{2}$ Faculty of Business administration, Laval University, Quebec City, Canada \\ Correspondence: Hager Khechine, Pavillon Palasis-Prince, 2325 Rue de la Terrasse, office 2527, Laval \\ University, Quebec City, G1V 0A6, Canada. Tel: 1-418-656-2131 ext. 7627. E-mail: \\ Hager.Khechine@sio.ulaval.ca
}

Received: May 14, 2013 Accepted: May 27, 2013 Available online: June 15, 2013

doi:10.11114/jets.v1i2.139

URL: http://dx.doi.org/10.11114/jets.v1i2.139

\begin{abstract}
Previous studies on podcasting assessed the usage impact of this technology on some cognitive and affective variables such as learning, performance efficiency, satisfaction and anxiety. However, these studies assumed that students had adopted podcasting without questioning their opinions. In order to reach a deeper understanding of students' perception of podcasting, this study aimed at examining two aspects: the advantages and the disadvantages of podcast use. A case study relying on open-ended questions was conducted among 130 participants enrolled in an online undergraduate business course. Obtained results indicated that practical aspects of use of this technology, such as improving attention and facilitating note-taking, dominated among the advantages. Lack of interaction and visual contact was one of the most notable disadvantages. This study could help enrich existing theoretical writings and empirical research about podcasts. It practical contributions would lead professors and educational tool creators to think about the relevance of developing and using podcasts for academic purposes.
\end{abstract}

Keywords: Online learning, Podcasting, Case study, Advantages, Disadvantages

\section{Introduction}

Information and communication technologies have been widely used in instruction and training over the past decades. The introduction of these technologies favored the emergence of new educational approaches and improvements in information organization, course content, and collaborative learning (Shelma \& Nachmias, 2007). Several universities were quick to benefit from these advantages by introducing these technologies in in-class and distance courses. Podcasting is amongst the technologies that contributed to decrease feelings of isolation caused by distance learning. Podcasting is a form of audio recording which stimulates the audience by transmitting verbal messages to the listeners (Smaldino, Russel, Heinich \& Molenda, 2005). Audio files are downloaded and listened to on different means such as computers, MP3 players, and iPods (Janossy, 2007; Lee \& Chan, 2007). Most empirical studies conducted on podcasting have evaluated the usage impact of this technology on variables dealing with intellectual functions (learning and performance efficiency - measured by educational results) and variables related to affect or subjective and emotional characteristics (satisfaction, anxiety, autonomy, participation, and motivation) (Evans, 2008; Khechine, Lakhal \& Pascot, 2009; Lakhal, Khechine \& Pascot, 2007; O’Bannon, Lubke, Beard \& Britt, 2011; Vajoczki, Watt, Marquis \& Holshausen, 2010). However, these studies assumed the adoption of podcasting by students whatever their acceptance of the technology and without questioning the social dimension of the academic setting (Caron, Caronia \& Weiss-Lambrou, 2007). Some attempts to test student preferences and opinions were done on other online educational technologies. For instance, Temple, Kemp and Benson (2006) assessed learner preferences for using computer-based technology in distance education. In this study, most respondents supported the idea of having a frequently asking question section on the website and e-mailing their tutor. However, they were reluctant to chat rooms and to the use of computer-based course material. Park, Crocker, Nussey, Springate and Hutchings (2010) asked graduate students enrolled in health profession courses to give their opinion about their experience in using Wiki technology. Most of the participants felt frustrated because Wiki did not operate as expected or 
because of technological problems. They also thought that Wiki did not add value to the group work. Crandall, Lim and Ro (2010) study reported that students appreciated the ANGEL online course management system because it allowed them to find everything in one place, to access missed materials, and to better communicate. Moreover, PowerPoint slides remained the most appreciated educational technology. This result was also obtained by Lawlor and Donnelly (2010). Their survey revealed that Ph.D. students preferred key-point slides supported by explanatory voice-over.

Most of the empirical studies described above have dealt with cognitive and affective impacts of podcasting. More particularly, they have placed emphasis on the improvement of students' performance, learning and comprehension. Some other empirical studies addressed students' perceptions (positive or negative) of the use of podcasts. However, they approached the problem in various manners using research questions, methodologies and objectives different from ours. The only study whose objectives and results were close to those of our research, but did not really match them, was that of Scutter, Sawyer and King (2010). Among a sample of eighty students enrolled in a medical program, they tried to get information about the advantages, the problems using podcasts and the moment when podcasts are listened to. Many features made the research of Scutter et al. (2010) different from our study. Firstly, their sample was made of medical students whose characteristics differ from those of business students. Business students are known to be different from other students on many aspects, such as personality (Lounsbury, Smith, Levy, Leon, \& Gibson, 2009), approaches to study (Elias, 2005), preference for technology (Kvavik, Caruso, \& Morgan, 2004), etc. Secondly, they used closed-ended questions, which made their answers limited to some predetermined items. Even though free text comments were permitted, responses were essentially focused on the advantages and their succinct analysis.

We thus deem it relevant to improve the understanding of podcast users' viewpoints in the business field by focusing on two facets: advantages and disadvantages. Study results could help building a theoretical basis for future research and would enrich existing literature. From the theoretical contribution, practical recommendations would be provided to professors who create podcasts. Teachers could learn from students' opinions in order to improve and adapt the content and the form of the recordings to learning purposes. These motivations and possible contributions led us to formulate two research questions as follows: 1) What are the perceived benefits of podcasts by students? 2) What are the perceived limitations of podcast use?

\section{Literature Review}

Given the infatuation of recent generations for a mobile culture supported by cell phones, MP3 players and portable computers, podcasting seems to attract the attention of professors who see in it the means to strengthen students' interest in learning. In most cases, professors create their own podcasts in order to support their teaching strategy (Ng'ambi, 2008). Some other professors encourage students to create podcasts in order to improve some desired skills in higher education such as critical thinking and teamwork (Armstrong, Tucker, \& Massad, 2009). However, according to Caron et al. (2007), students are brought to use podcasts but are never asked about the cultural and social issues involved. A review by Hew (2009) presented the results of studies on the use of podcasting in university settings. The themes of these past studies were classified into three categories: 1) Participants' podcast usage profile (current practices, listening preferences, and barriers); 2) Effects of podcasting on student cognitive and affective outcomes; and 3) Students' absenteeism and audio recording production costs. For the following paragraphs, Hew's review and other recent studies were used to build our literature review which dealt with two topics: advantages and disadvantages.

\subsection{Advantages of Podcasting}

Upon examination of the literature, the advantages of podcasting could be grouped into two categories. The first category contains cognitive advantages which are related to the intellectual and emotional experience when listening to podcasts. Learning, performance, understanding, and anxiety are considered as some of these cognitive characteristics. The second category is made of spatial and temporal advantages which refer to the ability of students to gain time and to choose the adequate place to follow a course thanks to podcasts.

Some descriptive studies focused on cognitive advantages (Bongey, Cizadlo \& Kalnbach, 2006; Clark, Sutton-Brady, Scott \& Taylor, 2007; Evans, 2008; Janossey, 2007; Kennedy \& Newman, 2012; Lane, 2006; Lee \& Chan, 2007; Ng'ambi, 2008; Scutter et al., 2010). Using qualitative and quantitative procedures, Lee and Chan (2007) attempted to identify the views, experiences and perceived learning values of students that used podcasts among 18 undergraduate computing and information technology Australian students. The majority of the participants reported that they have improved their learning and reduced anxiety generated by distance learning. The advantages perceived by these students were clarification and improvement of understanding, reinforcement of learning, and more efficient effort allocation. Through statistical analyses, Kennedy and Newman (2012) have proven that students who learned by watching content acquisition podcasts outperformed 
significantly students who used other material related to the general education field. Similar results were reported by Morris (2010) in a study involving 100 students enrolled in a cognitive neuroscience module. The effect of podcasting on student understanding and performance was also addressed by Janossy (2007) who used a sample of 92 college students enrolled in an introductory course in information technology. Less than half of the participants noted improvement in their learning and a positive effect on their course performance. One third of the students used the audio recordings for review before tests, exams or class sessions. Half of the participants used podcasts before doing the readings. In a study conducted among 196 undergraduate business and management students in Great Britain, Evans (2008) found that podcasting was considered to be a quicker way to revise than using notes and a more effective learning support than the readings proposed by the professor. Scutter et al. (2010) also asked students from the medical field about the advantages of the podcasts. Most of them highlighted the revision for exams and the clarification of issues or questions. A telling-story methodology used by Ng'ambi (2008) on 17 learners illustrated ways that podcasts could scaffold expansive learning beyond the limitation of traditional classrooms. For example, students said that podcasts allowed them to learn a lot from the class, made them able to follow the seminar in a deep and critical way and made them think that it is a good tool to use by groups. A study of Hill, Nelson, France and Woodland (2012) allowed concluding that video podcasts were proven to support learning through flexibility and visual capabilities. They were especially used by students in biogeography for revision and assessment. No effect on grades was noted.

Spatial and temporal advantages were both reported by Evans (2008). This author mentioned that students valued the flexibility allowed by podcasts as this technology permitted "to study where and when you want" ( $\mathrm{p}$. 495). Lee and Chan (2007) reported one sole spatial advantage pertaining to the mobility offered by audio recordings: accessibility of podcasts on most audio peripheries at any time. Being able to hear the lecture again was the most cited advantage by medical students surveyed by Scutter et al. (2010). The advantage of using podcasts in the case of missing a course was one of the temporal advantages revealed by Lane (2006). This author used a questionnaire to identify listening and habits of use of audio recording among 41 health sciences students. The questionnaire also embedded open-ended questions asking for the strengths and weaknesses of podcasting technology.

\subsection{Disadvantages of Podcasting}

The disadvantages of podcasting could be split into four categories: demotivating factors, absence of social and personal interaction, technological factors, and classroom session proceeding (Bongey et al., 2006; Caron et al., 2007; Fitcher, 2006; Hew, 2009; Lane, 2006; Maag, 2006).

The most cited demotivating factor in publications was absenteeism. However, few empirical studies confirm that podcasting was associated with absenteeism (Hew, 2009). For example, Bongey et al. (2006) concluded that listening to audio recordings had little effect on absenteeism. The results of the study of Lane (2006) were less conclusive in that students denied the effect of podcasting on absenteeism, while professors asserted the existence of such an effect.

With regard to social and personal interactions, previous studies reported that podcasting offered unidirectional communication, as interactions with the professor and other students were limited or even absent (Fitcher, 2006; Hew, 2009). As such, according to the participants to Lane's (2006) study, it wasn't possible to access visual material and to follow classroom discussion simply by listening to the recordings.

Technological limitations were often considered as an important barrier to podcasting use (Hew, 2009). Students and professors must have the adequate material and software infrastructure to create, publish, download, and listen to audio recordings (Fichter, 2006). Technical support, maintenance, and availability of servers and bandwidth are other technological challenges related to podcasting (Maag, 2006). Caron et al. (2007) considered that a technology adopted with difficulties contributes to strengthening resistance to its use in learning. Nonetheless, given the rapidity of technological evolution and the facility of individual adoption, this limitation was refuted by other authors who think that podcasts are relatively easy to produce, publicize and access (Lorenzo, 2006). Within this context, Lee and Chan (2007) reported no negative podcast access and listening experiences by students. The technical difficulties cited in Lane's (2006) study were limited to the quality of sound and the inability to find specific information within audio recordings. Scutter et al. (2010) also reported that poor sound quality was the main problem encountered by podcast listeners.

Classroom session proceeding was seen as the forth disadvantage of podcasting. Gribbins (2007) wrote that recording contents depended on podcast purposes. Shim, Shropshire, Park, Harris and Campbell (2006) suggested that recordings should contain additional class material. Furthermore, the record length was often a source of annoyance, as it was reported by some podcast users. Some authors believe that students demonstrated 
better attention when the material transmitted via the audio did not exceed 20 minutes length (Anzai, 2007; Chan \& Lee, 2005; Muppala \& Kong, 2007).

\section{Methodology}

\subsection{Participants}

Study participants were students enrolled in an undergraduate information system course offered by a large Association to Advance Collegiate Schools of Business (AACSB) and European Quality Improvement System (EQUIS) accredited faculty of business in Quebec City (Canada) at the end of the 2007 winter semester. The course was offered online via WebCT for 12 weeks. Supplementary classroom sessions were available for students but presence was not compulsory. These classroom sessions, which were recorded, served to explain the material already available online. Podcasts took then the form of "Complementary podcasts" as defined by Taylor and Clark (2010). A total of 130, of 308 registered students, responded to an online questionnaire on a voluntary basis. This specific course was chosen because it used podcasts and it had a large number of students enrolled.

Table 1. Sample description

\begin{tabular}{|c|c|c|c|c|c|}
\hline \multicolumn{2}{|c|}{ Gender } & \multicolumn{2}{|c|}{ Age } & & \\
\hline Male & Female & $<25$ years & $\geq 25$ years & & \\
\hline $69(53.1 \%)$ & $61(46.9 \%)$ & $110(84.6 \%)$ & $20(15.4 \%)$ & & \\
\hline \multicolumn{2}{|c|}{ Study plan } & \multicolumn{2}{|c|}{ Computer possessed from } & & \\
\hline Full-time & Part-time & At least 2 years & Less than 2 years & & \\
\hline $112(86 \%)$ & $18(14 \%)$ & $120(92.3 \%)$ & $10(7.7 \%)$ & & \\
\hline \multicolumn{2}{|c|}{ Course Nature } & \multicolumn{4}{|c|}{ Number of recordings listened to } \\
\hline $\begin{array}{c}\text { Mandatory } \\
119(91.5 \%)\end{array}$ & $\begin{array}{c}\text { Optional } \\
11(8.5 \%)\end{array}$ & $\begin{array}{c}\text { At least 2 } \\
42(32.3 \%)\end{array}$ & $\begin{array}{c}2 \text { to } 6 \\
29(22.3 \%)\end{array}$ & $\begin{array}{c}7 \text { to } 9 \\
20(15.4 \%)\end{array}$ & $\begin{array}{c}\text { More than } 10 \\
39(30 \%)\end{array}$ \\
\hline
\end{tabular}

As we can see in Table 1, among the 130 participants, $53.1 \%$ were male, $84.6 \%$ were less than 25 years old, $86 \%$ were registered in full-time studies, and $92.3 \%$ had possessed a computer for at least 2 years. The course selected for this study was mandatory for $91.5 \%$ of the enrolled students. Of the 130 participants, 42 noted they have listened to at least 2 of the 12 recordings, 29 between 2 and 6,20 between 7 and 9 , and 39 more than 10 .

\subsection{Procedure and Instrument}

This research fitted interpretive approach because it attempted to understand the phenomena of podcast use by capturing human thought and behaviour (Klein \& Myers, 1999). It took the form of a case study with open-ended questions. The choice of this methodology was justified by many arguments. Considering the research objective, this methodology seemed to be appropriate as it permitted to answer the research questions, to capture opinions, to explore the domain and to discover new research tracks (Boutin, 2008). Moreover, most studies conducted until now on podcasting used a quantitative - positivist - approach using multiple choice questions (Evans, 2008; Gribbins, 2007; Kennedy \& Newman, 2012; Khechine et al., 2009; Lakhal et al., 2007; Lee \& Chan, 2007; Morris, 2010; Scutter et al., 2010), which did not allow to deeply capture respondents' points of view (Hirschheim \& Klein, 2000).

Participants completed an online questionnaire comprised of two open-ended questions that addressed the advantages and disadvantages of listening to podcasts. The questions were:

1- What are the advantages of listening to audio recordings of the classroom sessions?

2- What are the disadvantages of listening to audio recordings of the classroom sessions?

In the middle of the session, one of the researchers went to the classroom and explained to the students the objective of the study and ensured them about the anonymity of their responses. Her presentation was recorded for distant students. Two weeks before the end of the session, a first e-mail, in which the Internet address of the questionnaire was embedded, was sent to all the students enrolled in the course. Two reminders were sent during the four weeks of data collection period. Participants transcribed their responses directly into the questionnaire website, thus enabling them to openly express themselves. To encourage student participation, three gift certificates were randomly drawn at the end of data collection.

\subsection{Coding Method and Data Analysis}

Regarding data coding, an initial coding tree, presented in Figure 1, was developed using a mixed approach: top-down and bottom-up. As our objective was to identify advantages and disadvantages of podcast use, the 
categories of analysis relied on this grouping. We then used the literature to identify the labels, which represented the results of previous studies or remarks made by previous studies' participants about their attitude. They were supported in Figure 1 by authors' references. These labels were then grouped into nodes. Each node aggregated labels semantically homogenous.

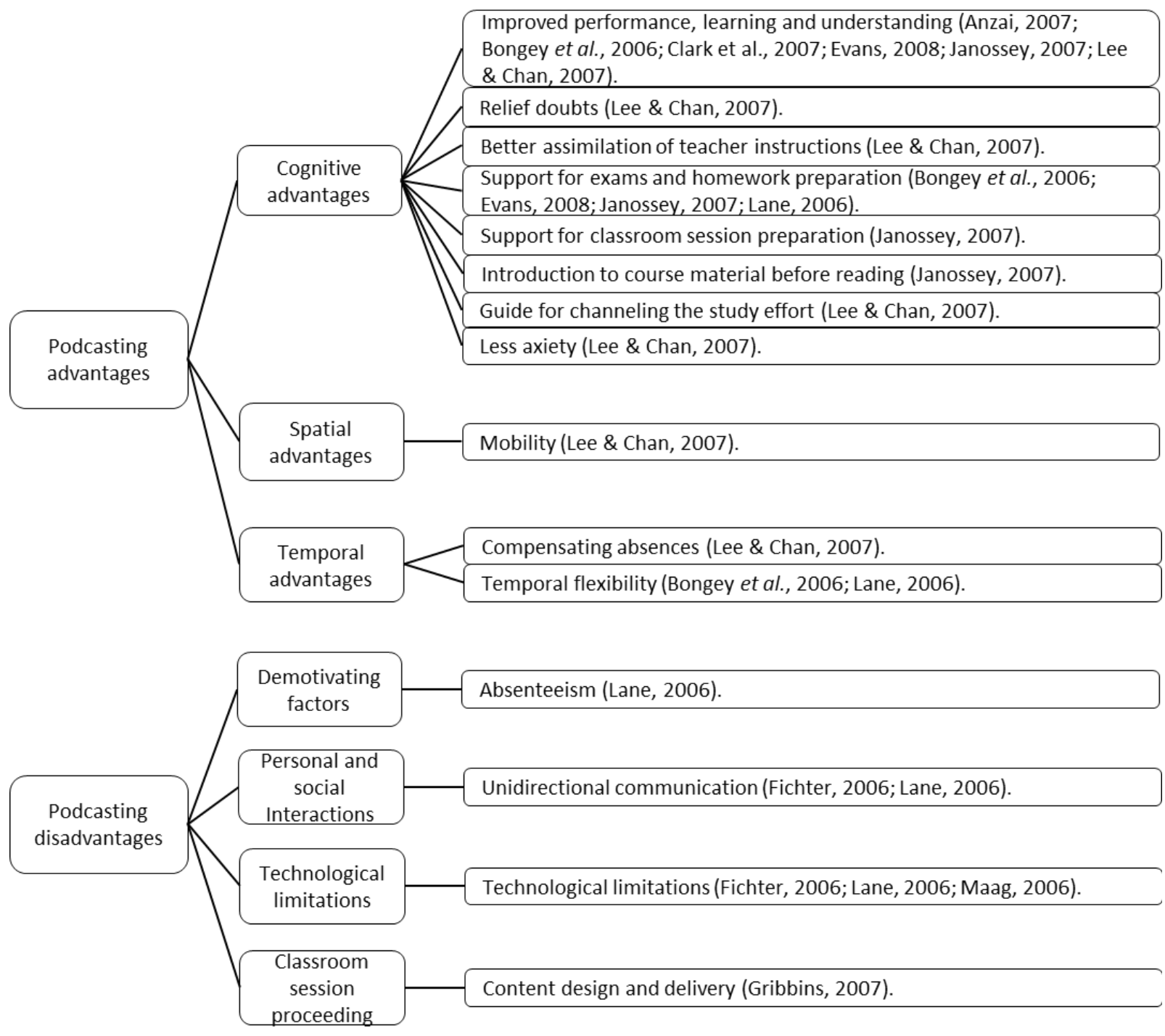

Figure 1. Initial coding tree

The method used to analyze students' remarks was content analysis (Miles \& Huberman, 1994). Students' comments were classified under the different labels according to their underlying meaning. New labels and nodes were added when additional themes emerged. A particular attention was also made to the number of occurrences of each label in the respondents' comments.

\section{Results and Discussion}

The results of this study are presented in two sections which correspond to the previously determined categories of analysis. For each section, the analysis of participants' remarks was presented. The initial coding tree was then adjusted by adding or eliminating nodes or labels following the results of content analysis.

\subsection{Advantages of Podcasting}

Content analysis of students' responses enabled building up five groups of advantages, each one corresponding to a tree node presented in Figure 2. It can be noted that, as compared to the sub-tree in Figure 1 regarding the advantages of podcasting, the tree in Figure 2 differs by the addition of a new node called "Technological advantages". With regard to the other nodes, as suggested by the literature, the cognitive advantages, the spatial advantages, and the temporal advantages seemed to encourage students to listen to podcasts. Nonetheless, the 
results of this study differed from previous studies by the importance attributed by the participants to each category of advantages. As it is explained further, and as can be seen on the tree labels in Figure 2, students' vision of the cognitive advantages was different than that drawn from the literature, as they evoked more elements. Moreover, the temporal and spatial advantages seemed to be of greater importance for the participants than were the cognitive advantages.

At the end of each sub-section detailing the advantages of podcasting, a table summarizes the results by indicating which specific advantages were cited in the literature and/or were found in our sample.

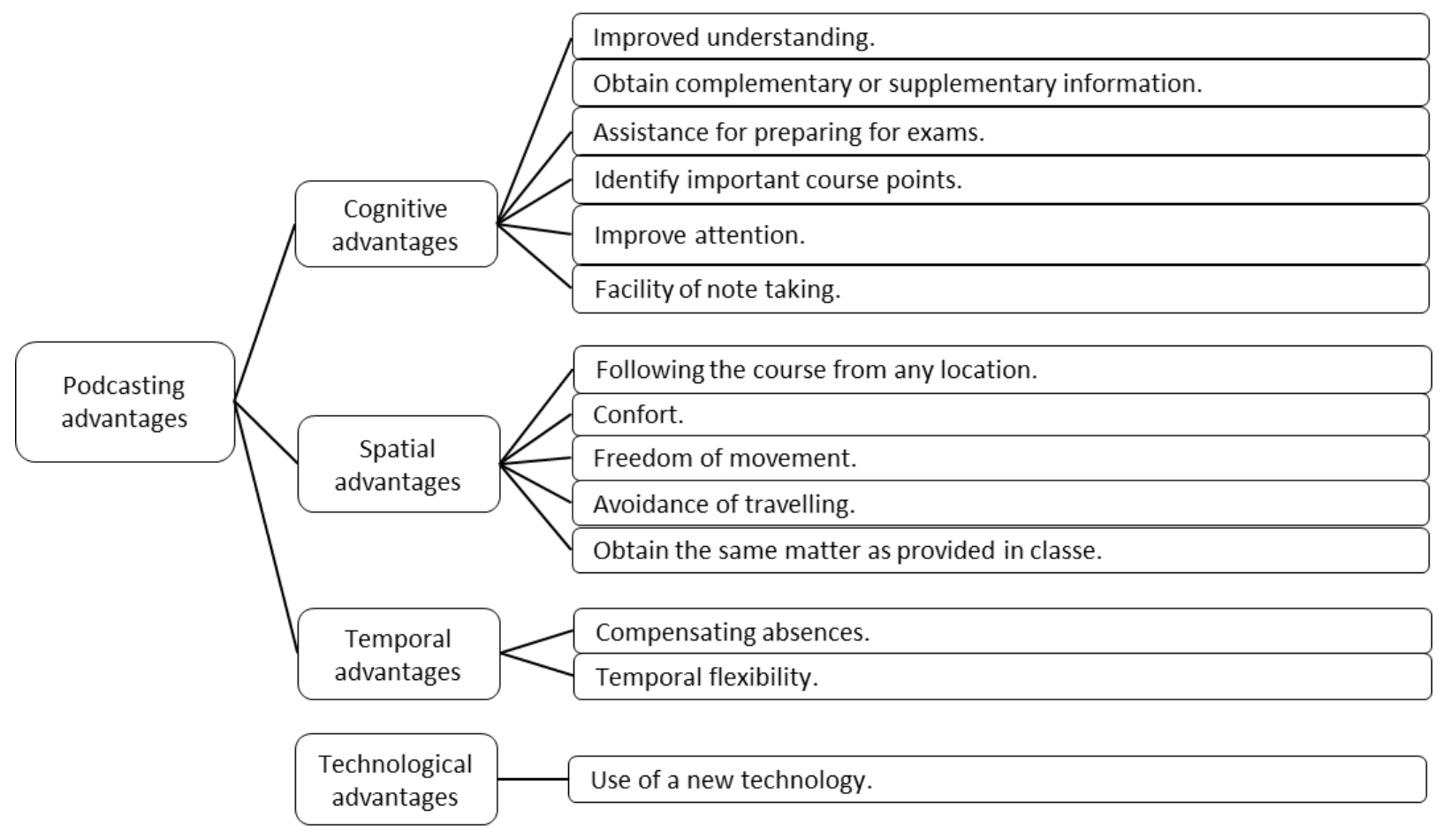

Figure 2. Podcasting advantages

\subsubsection{Cognitive Advantages}

Thirteen participants thought that audio recordings could improve their understanding of course material by offering them the opportunity to check again misunderstood concepts. This result corroborates those reported by Taylor and Clark (2010) where supplementary podcasts - as those listened to by the respondents of this research- helped reinforcing concepts for assessment tasks. However, participants did not evoke any improvement in performance or learning as it was widely suggested by previous research (Bongey et al., 2006; Clark et al., 2007; Evans, 2008; Janossey, 2007; Kennedy \& Newman, 2012; Lane, 2006; Lee \& Chan, 2007; Ng'ambi, 2008). This can be explained by the fact that data collection has begun two weeks before the end of the semester. At this stage of their learning, students were unable to comment on their performance, especially as in most previous studies, performance and learning were valued in terms of grades at the end of the semester.

According to a participant, audio recordings enabled him to obtain complementary or supplementary information. This argument was similar to one of the advantages cited in the literature, that of "relief doubts" (Lee \& Chan, 2007). However, no reference to professor instructions or to preparation of homework due throughout the semester was made. Note that in this course, the professor used podcasts to provide additional explanations regarding course material rather than clarification regarding homework. Details on course instructions were provided on the website in that the course was essentially offered online.

Only two students asserted that the use of podcasts has served as assistance for preparing for exams. One of them pointed out that:

'The professor mentions the important points of the content and the points to be remembered for the exam.'

This advantage seemed to be of a lesser importance for the study sample despite the fact that it stands out greatly in the literature review (Bongey et al., 2006; Evans, 2008; Janossy, 2007; Lane, 2006; Scutter et al., 2010). This 
result could be explained by the educational content of podcasts. In fact, this content dealt with a synthesis of the course material that would be insufficient to prepare for the exam, from the students' point of view. Consequently, assistance for preparing for the exam was not explicitly expressed as a major advantage.

No participant referred to the use of podcasts to further clarify the lectures or to prepare for classroom sessions, as mentioned by Janossy (2007). The absence of arguments regarding this aspect can be explained by the fact that the classroom session was given mid-week and the availability of the recording was not instantaneous. Students were thus required to read on the course material on the beginning of the week in order to follow the online course. Furthermore, podcasts consisted of audio recordings of the classroom session. They were therefore unavailable to students before the course was held.

Students also identified other cognitive advantages that improve teaching and learning. These advantages corroborate in part those cited in the literature. Indeed, two participants judged that podcasts enabled them to identify important course points. One student expressed this advantage as follows:

'If you are sick during a course or if you miss it, it's possible to not fall behind and to see which points are important in the course.'

Lee and Chan (2007) attributed this advantage to a broader advantage category in that they considered podcasts as an efficient tool to better allocate study efforts. These authors also cited the reduction of anxiety as a second cognitive advantage. The absence of students' comments about these advantages was not surprising considering that in a quantitative study conducted by Khechine et al. (2009) among business administration students, no link between podcasting use and anxiety was revealed. This affective state did not seem to play an important role in students' course learning.

Nonetheless, two advantages cited by the students distinguished our findings from those of previous studies. The first was cited by four students who reported that podcasts enabled them to improve students' attention. Indeed, classroom presence seemed to be a source of distraction caused by the noise of other students or by the use of portable computers. When students did choose the place and the moment to listen to a podcast, they created a study environment that improved their attention. One participant pointed out:

'What's more, you're not distracted by the others who whisper or who chat on MSN!'

The second advantage was evoked by two other students who revealed that audio recordings facilitated note-taking since it was possible to adapt the rhythm of the listening to the cadence of assimilation of course material, by stopping the recording, fast forwarding it, or rewinding it. One participant reported that:

'...note taking becomes extremely efficacious: it is possible to listen to passages over again, to press "pause" or to listen to it at two different times - at time when I feel more efficient...'

Table 2. Summary of the cognitive advantages

\begin{tabular}{lcc}
\hline \multicolumn{1}{c}{ Cognitive advantages } & $\begin{array}{c}\text { Our sample } \\
\text { (Number of students) }\end{array}$ & Literature \\
\hline Improved understanding & 13 & $\sqrt{ }$ \\
Obtain complementary or supplementary information & 1 & $\sqrt{ }$ \\
Assistance for preparing for exams & 2 & $\sqrt{ }$ \\
Identify important course points & 2 & - \\
Improve attention & 4 & - \\
Facility of note taking & 2 & - \\
\hline
\end{tabular}

Table 2 is a summary of the cognitive advantages. The symbol $\sqrt{ }$ is added in the literature column indicating that the concerned advantage was cited by previous research. Numbers in "Our sample" column indicate the number of students that reported the advantage in our sample.

\subsubsection{Spatial Advantages}

Lee and Chan (2007) evoked spatial advantages to a unique vision relating to mobility. Indeed, part of the literature attributed to podcasting the merit of flexibility by enabling one to listen to recordings in a non-sedentary position, thanks to MP3 players (Hew, 2009). However, this latter advantage was identified by only one participant who listened to recordings during long driving routes. Nevertheless, most of the students listened to the recordings at home on personal computers, as was confirmed by several empirical studies (Caron et al., 2007; Copley, 2007; Evans, 2008; Hew, 2009; Lane, 2006). A constraint relating to the audio file format 
(.ogg extension), which cannot be listened to on a drive other than a computer, may explain this finding. Mobility was not among the labels associated with spatial advantages because the study participant who mentioned it did not explicitly consider it to be an advantage. Another interpretation of this result could be that mobility was not important for the study sample. Indeed, they were enrolled in an online course, making them able to follow it from home or sometimes work. So, the mobility was already offered by the distant learning and was not a novelty brought by podcasting.

Given that the study sample was comprised of students following a distance course and that some of them were on labor market, other dimensions emerged from their responses. Twenty-three participants found that following the course from any location represented a major advantage. Most students listened to recordings at home when they were alone, in absence of family members, which guaranteed them a peaceful study environment. One participant reported that podcasting was:

'an easy means within one's reach that makes it possible to stay within the comfort of one's home...'

Other students listened to the recordings at the university, given that downloading audio files was more rapid. Others did so at work when the listening conditions of other places were not favorable to learning and attention.

Comfort was a second dimension related to the spatial advantages cited by six students. Listening to a recording after choosing the exact location (room, basement, etc.) and posture (lying down, sitting) was one option that certain students appreciated. One student said that he listened to recordings:

'...at home, sitting comfortably on the couch, with my coffee and toast!'

Freedom of movement was evoked by four participants as an advantage of podcasting. This referred to the possibility of listening to recordings while carrying out other tasks in a location of their choice. The accessibility of podcasts at home, for example, gave them the freedom to simultaneously take on other activities such as household tasks. Indeed, one student admitted:

'I can do other things at the same time, fold laundry...'

Given that the course was provided online and that several students enrolled lived in distant regions or are employed, avoidance of traveling was perceived to be a major advantage according to twenty-four students. Among the many related comments, the following was retained:

'No useless traveling to the University. Possible to listen at the time and place of my choosing...'

Finally, three students found that using podcasts had the advantage of enabling them to obtain the same matter as provided in class. Given that the course used a mixed format (by Internet and in class), the availability of audio recordings of the course attenuated the feeling of being at a disadvantage as compared to students who could attend the classroom session. According to one participant:

'The advantage is that we can use the same material as we would if we went to class, but we can comfortably access it from home.'

Table 3. Summary of the spatial advantages

\begin{tabular}{lcc}
\hline \multicolumn{1}{c}{ Spatial advantages } & $\begin{array}{c}\text { Our sample } \\
\text { (Number of students) }\end{array}$ & Literature \\
\hline Following the course from any location & 23 & - \\
Comfort & 6 & - \\
Freedom of movement & 4 & - \\
Avoidance of traveling & 24 & - \\
To obtain the same matter as obtained in class & 3 & - \\
\hline
\end{tabular}

Like Table 2, Table 3 summarizes the spatial advantages. Following the course from any location and avoidance of traveling were the most cited spatial advantages. This result confirms that students were looking more for practical advantages than for cognitive ones.

\subsubsection{Temporal Advantages}

Findings concerning temporal advantages corresponded to the two initial coding tree labels of Figure 1 identified through the literature (Bongey et al., 2006; Lane, 2006; Lee \& Chan, 2007). Indeed, seventeen students reported that the availability of podcasts enabled them to compensate for absences from the course. As for Bongey et al. (2006), several participants preferred listening to recordings rather than borrowing course notes from other 
colleagues. This gave them the feeling to be physically present and that they did not miss professor explanations. One participant believed that podcasting made:

'... know the course content and to not be disadvantaged in comparison to other students who attended class, regardless of geographic situation.'

Temporal flexibility was very cited by participants and recurrently mentioned by the literature (Evans, 2008; Lane, 2006; Lee \& Chan, 2007; Taylor \& Clark, 2010). Forty-five students reported temporal flexibility to be of a great advantage. The availability of course recordings offered students the possibility of conveniently managing their time while experiencing special circumstances such as a busier week or exam preparation for other courses. When students did choose the moment they listened to their course, they found they were faced with fewer constraints, felt they had more freedom, and considered it to be an occasion to develop their sense of responsibility and autonomy. According to a student:

'Listening later enables me to manage my time differently. If I have a week that is fuller because another course is taking up a lot of my time, I can take my Wednesday morning to work on the other course and listen to this course over again at home during the weekend. It is freedom, a sense of responsibility and autonomy that is given to students...'

Table 4. Summary of the temporal advantages

\begin{tabular}{lcc}
\multicolumn{1}{c}{ Temporal advantages } & $\begin{array}{c}\text { Our sample } \\
\text { (Number of students) }\end{array}$ & Literature \\
\hline Compensating absences & 17 & $\sqrt{ }$ \\
Temporal flexibility & 45 & $\sqrt{ }$ \\
\hline
\end{tabular}

Table 4 is a summary of the temporal advantages. Once again, practical advantages outstrip cognitive ones.

\subsubsection{Technological Advantages}

The technological advantages node with the label use of a new technology was introduced into the coding tree after the analysis of students' responses. This advantage was cited by one student who saw in podcasting a new opportunity. He believed that the use of this technology brought changes in his learning methods. He expressed this advantage as follows:

'It forces us to use a new work instrument, to face changes and to benefit from new opportunities provided by the technology.'

This result is peculiar because this respondent was amongst the younger students in the course (under 20 years) and one of the four students that had possessed a computer from less than six months. His lack of familiarity with computers made him see podcasts as a technological opportunity to overcome this gap.

Table 5. Summary of the technological advantages

\begin{tabular}{ccc}
\hline Technological advantages & $\begin{array}{c}\text { Our sample } \\
\text { (Number of students) }\end{array}$ & Literature \\
\hline
\end{tabular}

Use a new technology

The number of students that evoked the technological advantages and the absence of literature about it are presented in Table 5.

\subsection{Disadvantages of Podcasting}

As shown in Figure 3, analysis of students' responses concerning the perceived disadvantages of podcasting revealed five nodes, one of them was absent from the existing literature (Temporal factors). The labels corresponding to the other four nodes differ from those of Figure 1, notably for the Technological factors and Classroom session proceeding nodes. Demotivation Factors and Social and personal interactions nodes were enriched by new labels. Another interesting result that emerged for the disadvantages was that some of them were already considered as advantages like excess of flexibility vs. flexibility, distraction vs. improvement of student attention, distraction vs. freedom of movement, and demotivation vs. temporal flexibility. 


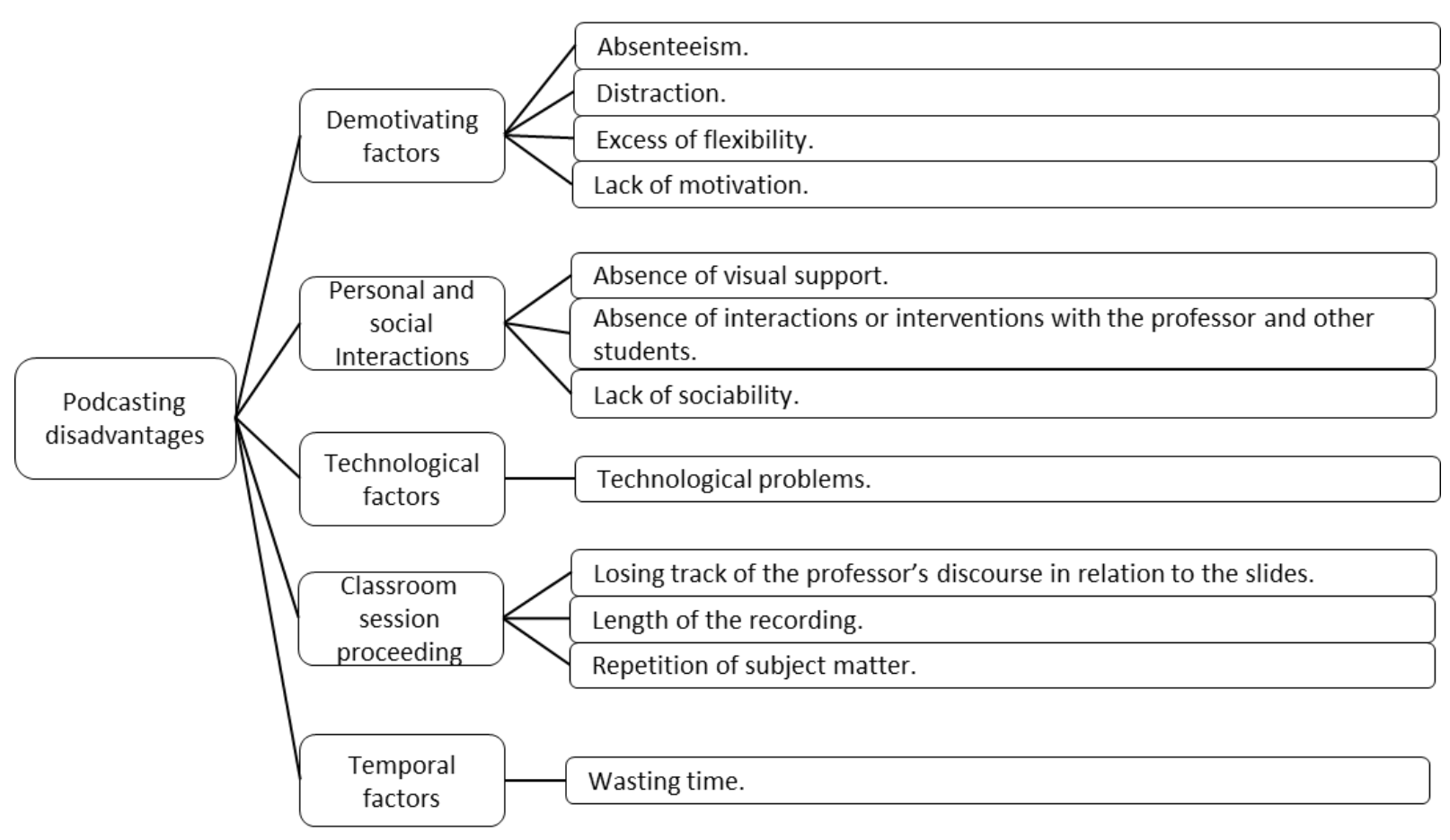

Figure 3. Podcasting disadvantages

\subsubsection{Demotivation Factors}

Most theoretical writings and empirical research emphasized absenteeism as the principal hindrance to the adoption of podcasting in education. In our sample, only two participants identified this point as a disadvantage. Indeed, absenteeism did not represent a major barrier within the scope of this course given that it was essentially offered online and classroom presence was not compulsory. One participant expressed this disadvantage as follows:

One inconvenience would be that we are less motivated to attend class and sometimes we tend to neglect its importance given that the course is recorded.'

Nevertheless, it seems that the availability of podcasts has had some effect on absenteeism because more than a half of the respondents have attended less than $50 \%$ of the classroom sessions.

Students who participated to this study expressed other demotivation factors like distraction. Sixteen students believed that they were less attentive at home, as this environment was less controlled than that of a classroom. Attention was thus decreased by various sources of distraction such as telephone ringing, people interrupting, and temptation to do other activities simultaneously. Distraction was reinforced by the absence of images or visual stimulation for certain participants. One participant thought that:

'...Only having the sound and no image is very distracting, at least for me. I find that it's a lot easier to be attentive when we have something to look at. When we listen to the course, it is much easier to be distracted and lose track of the course we are listening to.'

These results contradict what we argued earlier about freedom of movement and improvement of student attention, which were seen as advantages. Indeed, improving student attention was cited as an advantage for some students for whom classroom presence was a source of distraction caused by the presence of other students. Considering distraction and student attention factors as advantages or disadvantages is tributary to many factors such as the family environment of the student, his personality, and his learning habits.

Four students reported that the advantage related to listening flexibility could turn into an inconvenience, as the excess of flexibility may result in not listening to the recordings. Given that a student had the choice to listen or not to the recording, it is easier to interrupt listening at a desired moment, to skip parts of the recording, to procrastinate or to never listen to the podcast again. Other students reckoned that it was easy to skip sessions or to put listening off until later, thus placing them at risk for forgetting or never finding the time to do so. This 
disadvantage is specific to the optional listening context of audio recordings. One participant expressed this inconvenience in the following manner:

'Very easy to say oh! I'll listen to it tomorrow! And then end up never listening to it.'

Lack of motivation was a disadvantage cited by six participants. Certain students who are used to a study in an environment where learning is reinforced by the presence of people who share the same experiences were less motivated to listen to the recordings because of feeling of isolation. Indeed, finding oneself at home, and listening to the course alone on the computer were factors that contributed to the loss of motivation reported by participants. One student found that:

'It is less motivating to listen to a course alone with one's computer... not very interactive.'

Once again, this demotivation factor depends on the personal characteristics of students. It is important to notice that this disadvantage was also classified as an advantage because some students considered flexibility as a good asset provided by podcasts.

Table 6. Summary of the demotivation factors

\begin{tabular}{lcc}
\hline \multicolumn{1}{c}{ Demotivation factors } & $\begin{array}{c}\text { Our sample } \\
\text { (Number of students) }\end{array}$ & Literature \\
\hline Absenteeism & 21 & $\sqrt{ }$ \\
Distraction & 16 & - \\
Excess of flexibility & 4 & - \\
Lack of motivation & 6 & - \\
\hline
\end{tabular}

Table 6 contains the demotivation factors that were identified by the students of our sample. Only absenteeism was reported by previous studies.

\subsubsection{Social and Personal Interactions}

The absence or lack of social and interpersonal interactions was one of the most cited disadvantages by participants. This result was confirmed by several empirical studies criticizing podcasting for favoring unidirectional communication (Fichter, 2006; Lane, 2006). According to the participants of the present study, unidirectional communication takes place on several forms and assumes various meanings. Indeed, the students expressed this disadvantage according to three axes: the absence of visual support, the absence of interactions, and the lack of sociability.

The absence of visual support and the absence of interactions and interventions with the professor and other students were the two most cited disadvantages (twenty-three and twenty-four participants). Visual support covered visualization of the professor who was giving the course. For some students, learning could be facilitated by visual contact with the professor and the course content. The absence of this contact lessened their attention, their interest, or their understanding. It thus appeared that PowerPoint presentations provided by the professor were insufficient to meet this need. Some participants even suggested substituting audio recordings with video recordings in order to improve direct contact with the professor. This solution was adopted by Hill et al. (2012). They concluded that the visual nature of video podcasts helped students with their understanding. Indeed, voice expresses several nuances in the subject matter taught and seeing gestures would improve learning of those with a visual memory. According to one of the participants:

'[The inconvenience is] that you can't see the professor. You have the tone, but you miss the gestures. It's important for people like me who have a visual memory.'

Participants also criticized podcasting for the lack of possible interactions and interventions such as those usually occurring in class. They evoked the absence of live leadership and direct communication with the professor and other students, and the lack of personalization. This result confirmed those of Fitcher (2006) and some arguments in Hew (2009). Even with video podcasts, students in the study of Hill et al. (2012) pointed out the lack of direct interaction. This inconvenience made them feel to be placed at the lowest stage of the affective hierarchy because they are only receiving information. One of the participants expressed this disadvantage as follows:

'The main inconvenience of listening to recordings of the courses is that you can't directly intervene, when you have questions you want to ask or when we wish to support the professor's idea.'

Nonetheless, these disadvantages were judged to be minor by other students, given that they represented limitations not specific to podcasting, but rather common to all distance learning courses. 
Lack of sociability was a disadvantage that was identified by one student who expressed it in the following way:

'We can't ask questions directly to the professor, we don't socialize.'

This limit was thus the consequence of both the lack of interactions with the professor and students and the feeling of isolation experienced within the scope of distance courses. Like the disadvantages previously cited, this one was not specific to podcasting, as it could be present in all distant courses. The participant evoked this disadvantage probably because his expectations regarding podcasting were high. Audio recordings were seen as a tool that could bring more life to a distance learning course and that would thus improve social relationships often erased by distance. Note that the student who expressed this disadvantage has attended most classroom sessions (more than 80\%) - even if the course was online - and has listened to no more than $20 \%$ of the podcasts available.

Table 7. Summary of the social and personal interactions

\begin{tabular}{|c|c|c|c|}
\hline \multicolumn{2}{|c|}{ Social and personal interactions } & \multirow{2}{*}{$\begin{array}{c}\begin{array}{c}\text { Our sample } \\
\text { (Number of } \\
\text { students) }\end{array} \\
23\end{array}$} & \multirow[t]{2}{*}{ Literature } \\
\hline \multirow{4}{*}{$\begin{array}{l}\text { Unidirectional } \\
\text { communication }\end{array}$} & Absence of visual support & & \\
\hline & Absence of interactions and & 24 & \multirow{3}{*}{$\sqrt{ }$} \\
\hline & $\begin{array}{l}\text { interventions with professors and other } \\
\text { studies }\end{array}$ & & \\
\hline & Lack of sociability & 1 & \\
\hline
\end{tabular}

The number of students that have cited the above elements related to social and personal interaction, described by literature as unidirectional communication, was shown in Table 7.

\subsubsection{Technological Factors}

Most studies on podcasting identified technical problems as an inconvenience of its use (Hew, 2009). These studies emphasized the need to have adequate material and software infrastructure to ensure proper functioning of audio recordings. Technical difficulties during the creation or downloading of podcasts decrease as technologies evolve and as broader and more reliable bandwidths are available. Given that the delivery mode of the course was online, students outside the campus had variable connection capabilities. One participant pointed out having difficulty downloading the audio file in "Dial-up" connection mode. Another student complained that he was unable to listen to course recordings even when he had assistance downloading the appropriate software. He thus suggested providing technical training on podcast use. We noted that technical problems, such as those presented in the literature, did not represent a significant concern for our participants. This could be explained by the familiarity of most students with the use of technologies given their young age $(84.6 \%$ are younger than 25 years) and their computer use antecedents (92.3\% used computers from at least 2 years). However, as pointed out by Lane (2006), Scutter et al. (2010), and by seventeen participants in our study, the major difficulty identified was related to the poor quality of recording sound. Indeed, for various reasons, some classroom courses were not recorded or were poorly recorded (professor's microphone placed incorrectly, inadequate functioning of the system, background noise of students present in class, etc.). These conditions inhibited the positive impressions of podcasting, as students were left with the feeling that they missed some of the subject matter. One participant attested to the situation:

'Once a session recording did not work and was never re-recorded, so I find that it's an inconvenience because we miss part of the material.'

Table 8. Summary of the technological factors

\begin{tabular}{clcc}
\hline & Technological factors & $\begin{array}{c}\text { Our sample } \\
\text { (Number of } \\
\text { students) }\end{array}$ & Literature \\
\hline $\begin{array}{l}\text { Technical } \\
\text { problems }\end{array}$ & Connection and downloading problems & 2 & $\sqrt{ }$ \\
\hline
\end{tabular}

Technological factors were summarized in Table 8. The poor quality of the sound was the dominant disadvantage related to technological problems.

\subsubsection{Classroom Session Proceeding}

Gribbins (2007) highlighted problems relating to the content of audio recordings. Since visual contact with professor and interaction with other students were not allowed by this technology, content of podcasts must be 
thought out and created according to these constraints. Mixing materiel designed for classroom with a learning management system such as recorded lectures will not necessarily generate value for students and professors (Taylor \& Clark, 2010). In this regard, Henry and Meadows (2008) argued that "great online courses are defined by teaching, not technology". Participants identified three disadvantages relating to classroom session proceeding. The first was expressed in terms of a losing track of the professor's discourse in relation to the slides presented. Indeed, the scroll-down of professor's slides did not automatically follow recorded speech. Students must thus change pages of professor's presentation according to their understanding of the matter being listened to. Accordingly, seven participants proposed that the professor should indicate any change in slide throughout recordings. The professor's conference and his preparation of recording contents must therefore take into account that he is addressing students not present in class. For one participant:

'The professor sometimes forgets that there are students not in classes and it is difficult to know where he is or where he's going.'

The second disadvantage relating to classroom session proceedings pertained to the length of the recording. Two students reported that podcasts were too long and sometimes even boring. This finding corroborated the conclusions of Chan and Lee (2005) and Muppala and Kong (2007) who reported that podcasts should be no longer than 20 minutes. In the Taylor and Clark (2010) study, respondents did not agree on the ideal length of a podcast episode. Varying from the length of a song to no more than 20 minutes, no student reported wanting a longer record. Factors such as a lack of interactivity, distraction, absence of visual support to retain listener's attention, and lack of motivation may explain this perception of lengthiness.

Finally, one student expressed his frustration regarding the repetition of subject matter, which pertains to the third disadvantage relating to the classroom session proceeding. He said:

'... We notice even more repetition of examples or subject matter (the audios should be prepared ahead of time and more structured than the course).'

According to this student, this repetition was associated with a lack of professor preparation and poor course structure. This result corroborates those of Taylor and Clark (2010) where 17\% of the students requested different information in podcasts to that presented elsewhere.

Table 9. Summary of the classroom session proceeding

\begin{tabular}{clcc}
\hline \multicolumn{2}{c}{ Classroom session proceeding } & $\begin{array}{c}\text { Our sample } \\
\text { (Number of students) }\end{array}$ & Literature \\
\hline \multirow{2}{*}{$\begin{array}{c}\text { Content design } \\
\text { and delivery }\end{array}$} & $\begin{array}{l}\text { Loosing track of the professor's discourse } \\
\text { in relation to the slides }\end{array}$ & 7 & $\checkmark$ \\
& $\begin{array}{l}\text { Length of the recording } \\
\text { Repetition of the subject matter }\end{array}$ & 2 & $\checkmark$ \\
\hline
\end{tabular}

Classroom session proceeding was described by the literature as a content design and delivery problem. However, as we can see in Table 9, students in this research expressed it in three ways.

\subsubsection{Temporal Factors}

Temporal factors represented a new node that wasn't identified in the literature review. The only label associated with this node was wasting time. Indeed, one student believed that listening to all the recordings increases the time necessary to complete the course. He said:

'... Listen to them all increases the time needed for the course by a lot.'

This student seemed to appreciate this course because it was online. Indeed, he attended less than $20 \%$ of the classroom sessions and he listened to no more than $50 \%$ of the recordings. As he was enrolled as a part-time student, evidence suggests that he was on labor market and that he lacked time to listen to long recordings.

Table 10. Summary of the temporal factors

\begin{tabular}{|c|c|c|}
\hline Temporal factors & $\begin{array}{c}\text { Our sample } \\
\text { (Number of students) }\end{array}$ & Literature \\
\hline Wasting time & 1 & - \\
\hline
\end{tabular}

As shown in Table 10, temporal factors are another group of disadvantages that literature and previous research have never talked about. 


\section{Conclusion, Implications and Directions for Future Research}

The objective of this study was to survey the perceptions of students who listen to podcasts regarding the advantages and disadvantages of use of this technology. For this purpose, we tried to answer two research questions: What are the perceived benefits of podcasts by students? and what are the perceived limitations of podcast use?

This study brought forth a foundation for understanding the perception of students about the use of podcasting in higher education. Most of previous studies have tried to assess the effectiveness of this technology on students' performance and learning. The originality of the present study resides in the fact that it gathered student opinions on different facets of its use, both positive and negative using an interpretive methodology. Obtained findings contributed to enriching existing knowledge through the addition of nodes and labels to an initial coding tree, developed based on the literature review. This knowledge could help instructors that develop podcasts' content make better decisions according to students' preferences, viewpoints and affinity. For instance, professors could think about techniques to synchronize slides to voice, to develop short recordings that avoid repetition. They have also to reinforce learning objectives and temporal and spatial flexibility that students seek.

At first glance, students' responses concerning cognitive advantages focused more on practical and direct implications of podcasts than on performance and learning improvement. This result can be explained by the nature of the podcasts and the context in which the study was conducted. Indeed, the records were supplementary to the course material. They did not provide new elements of knowledge, but they have served to improve understanding of the material available online and helped in identifying key points. So, students perceived podcasts as tools helping them improve "process" of learning rather than reaching a specific "goal" (i.e. academic performance). In addition, students were unable to comment on their performance since the assessment was disrupted by the strike during the session.

We noticed in the results that some advantages were also mentioned as disadvantages. We wonder if personal characteristics, learning styles, and academic major could have some influence on this finding. This is another issue that has to be explored to get a clearer understanding of the results.

The results of the present study could lead researchers, professors and educational tool creators to question the relevance of using podcasts to support student learning and to look forward for students' motives to listen to podcasts. Gribbins (2007) undertook a step in this direction by applying Technology Acceptance Model (TAM) to the context of podcasting. Other models, such as Unified Theory of Acceptance and Use of Technology (UTAUT) (Venkatesh, Morris, Davis \& Davis, 2003), could be adopted to bring additional responses to these questionings. This model could be applied to identify variables that drive students to use podcasts, such as facilitating conditions, effort expectancy, performance expectancy, and social influence. Moreover, knowing what students think about the contribution of podcasts in their learning could be helpful in deciding whether to support pedagogical strategy using this kind of technology. This information could be helpful for professors who want to improve their teaching strategy but are reluctant to this technology. Podcast developers would thus be invited to rethink the form and the content of audio recordings while taking into account students' perceptions. Cebeci and Tekdal (2006) raised the question about the relevance of podcast characteristics such as sequence, topical density, and individual length of fragments of audio learning objects. The form of podcasts (re-framed, complementary or supplementary) has also to be evaluated without forgetting that it is important to support the flexibility of podcasts with traditional learning framework like seminar discussion (Hill et al., 2012). Future research could use students' comments gathered by this study to further reflection about students' needs in terms of podcast content and form.

\section{References}

Anzai, Y. (2007). Empowering English learning utilizing podcasts. In G. Richards (Ed.). Proceedings of World Conference on E-learning in Corporate, Government, Healthcare, and Higher Education 2007, Chesapeake, VA: AACE, 10-15.

Armstrong, G. R., Tucker, J. M., \& Massad, V. J. (2009). Interviewing the experts: Student produced podcast. Journal of Information Technology Education: Innovation in Practice, 8, 79-90.

Bongey, S. B., Cizadlo, G., \& Kalnbach, L. (2006). Explorations in course-casting: Podcasts in higher education. Campus-Wide Information Systems, 23(5), 350-367. http://dx.doi.org/10.1108/10650740610714107

Boutin, G. (2008). L'entretien de recherche qualitatif. Québec : Presses de l'Université du Québec. 
Caron, A. H., Caronia, L., \& Weiss-Lambrou, R. (2007). La baladodiffusion en éducation : Mythes et réalités des usages dans une culture mobile. Revue Internationale des Technologies en Pédagogie Universitaire, 4(3), 42-57.

Cebeci, Z., \& Tekdal, M. (2006). Using Podcasts as Audio Learning Objects. Interdisciplinary Journal of Knowledge and Learning Objects, 2, 47-57.

Chan, A., \& Lee, M. J. W. (2005). An MP3 a day keeps the worries away: Exploring the use of podcasting to address preconceptions and alleviate pre-class anxiety amongst undergraduate information technology students. In D. H. R. Spennemann and L. Burr (Eds.), Good practice in practice. Proceedings of the Student Experience Conference 5-7th September'05. Wagga Wagga, NSW: Charles Sturt University, pp. 58-70.

Clark, S., Sutton-Brady, C., Scott, K. M., \& Taylor, L. (2007). Short podcasts: The impact on learning and teaching. In A. Austin \& J. Pearce (Eds.), Proceedings of mLearn Conference 2007, Melbourne, Australia, 285-289.

Copley, J. (2007). Audio and video podcasts of lectures for campus-based students: Production and evaluation of student use. Innovations in Education and Teaching International, 44(4), 387-399. http://dx.doi.org/10.1080/14703290701602805

Crandall, J. M., Lim, K. A., \& Ro, Y. S. E. (2010). The impact of IT: pedagogical perspectives in university education settings. Journal of International Business Research, 9(1), 23-31.

Elias, R. Z. (2005). Students' Approaches to Study in Introductory Accounting Courses. Journal of Education for Business, 80(4), 194-199. http://dx.doi.org/10.3200/JOEB.80.4.194-199

Evans, C. (2008). The effectiveness of m-learning in the form of podcast revision lectures in higher education. Computers \& Education, 50(2), 491-498. http://dx.doi.org/10.1016/j.compedu.2007.09.016

Fichter, D. (2006). Creating engaging audio content: Intranet Podcasting. Online, 30(6), 46-48.

Gribbins, M. (2007). The perceived usefulness of podcasting in higher education: A survey of students' attitude and intention to use. Proceeding of the 2nd Midwest Association of Information Systems Conference, Springfield, Illinois.

Henry, J., \& Meadows, J. (2008). An absolutely riveting online course: Nine principles for excellence in web-based teaching. Canadian Journal of Learning and Technology, 34(1).

Hew, K. F. (2009). Use of audio podcast in K-12 and higher education: a review of research topics and methodologies. Education Technology Research and Development, 57(3), 333-357. http://dx.doi.org/10.1007/s11423-008-9108-3

Hill, J., Nelson, A., France, D., \& Woodland, W. (2012). Integrating podcast technology effectively into student learning: A reflexive examination. Journal of Geography in Higher Education, 36(3), 437-454. http://dx.doi.org/10.1080/03098265.2011.641171

Hirschheim, R., \& Klein, H. K. (2000). Information system research at the crossroads: external versus internal views. In Organizational and Social Perspectives on Information Technology, Baskerville R., Stage J., DeGross J. I. (Dir.), Kluwer Academic Publishers, Boston, 233-254. http://dx.doi.org/10.1007/978-0-387-35505-4_15

Janossy, J. (2007). Student reaction to podcast learning material: Preliminary results. 12th Annual Instructional Technology Conference: Engaging the Learner. Tennessee, 98-120.

Kennedy, M. J., \& Newman T. C. (2012). Effects of content acquisition podcasts to develop preservice teachers' knowledge of positive behavioral interventions and supports. Exceptionality: A Special Education Journal, 20(1), 1-19. http://dx.doi.org/10.1080/09362835.2011.611088

Khechine, H., Lakhal, S., \& Pascot, D. (2009). Efficacité du podcasting en enseignement et apprentissage: Résultats empiriques pour un cours donné en formule mixte. Systèmes d'information et management, 14(1), 103-129.

Klein, H. K., \& Myers, M. D. (1999). A set of principles for conducting and evaluating interpretive field studies in information systems. MIS Quarterly, 23(1), 67-94. http://dx.doi.org/10.2307/249410

Kvavik, R. B., Caruso, J. B., \& Morgan, G. (2004). ECAR study of students and information technology 2004: convenience, connection, and control. Boulder, CO: EDUCAUSE Center for Applied Research. Retrieved May 31, 2012, from http://net.educause.edu/ir/library/pdf/ERS0506/ECM0506.pdf 
Lakhal, S., Khechine, H., \& Pascot, D. (2007). Evaluation of the effectiveness of podcasting in teaching and learning. Proceedings of the E-Learn World Conference on E-learning in Corporate, Government, Healthcare, \& Higher Education, Quebec, Canada, 6181-6188.

Lane, C. (2006). UW Podcasting: Evaluation of Year One. Catalyst, http://catalyst.washington.edu/research_development/papers/2006/podcasting_year1.pdf, retrieved: September 17, 2010.

Lawlor, B., \& Donnelly, R. (2010). Using podcasts to support communication sills development: A case study for content format preferences among postgraduate research students. Computers \& education, 54, 962-971. http://dx.doi.org/10.1016/j.compedu.2009.09.031

Lee, M. J. W., \& Chan, A. (2007). Reducing the effects of isolation and promoting inclusivity for distance learners through podcasting. Turkish Online Journal of Distance Education, 8(1), 85-104.

Lounsbury, J. W., Smith, R. M., Levy, J. J., Leon, F. T., \& Gibson, L. W. (2009). Personality characteristics of business majors as defined by the Big Five and narrow personality traits. Journal of Education for Business, 84(4), 200-206. http://dx.doi.org/10.3200/JOEB.84.4.200-205

Lorenzo, G. (2006). An introduction to Podcasting. Educational Pathways.

Maag, M. (2006). Podcasting and MP3 players: emerging education eechnologies. Computer Informatics Nursing, 24(1), 9-13. http://dx.doi.org/10.1097/00024665-200601000-00005

Miles, M. B., \& Huberman, A. M. (1994). Qualitative Data Analysis. 2nd ed., Sage, Thousand Oaks.

Morris, N. P. (2010). Podcasts and Mobile Assessment Enhance Student Learning Experience and Academic Performance. Bioscience Education, 16. http://dx.doi.org/10.3108/beej.16.1

Muppala, J. K., \& Kong, C. K. (2007). Podcasting and its use in enhancing course content. In V. Uskov (Ed.). Proceedings of the Ascilite Singapore 2007 Conference, 747-751, Singapore.

Ng'ambi, D. (2008). Podcasts for Expansive Learning: A Case of Reflective Student Stories. South African Computer Journal, 42, 9-13.

O'Bannon, B. W., Lubke, J. K., Beard, J. L., \& Britt, V. G. (2011). Using podcasts to replace lecture: Effects on $\begin{array}{lllll}\text { student } \quad \text { achievement. Computers } \quad \& \quad \text { Education, } & \text { 57, }\end{array}$ http://dx.doi.org/10.1016/j.compedu.2011.04.001

Park, C. L., Crocker, C., Nussey, J., Springate, J., \& Hutchings, D. (2010). Evaluation of a teaching tool - Wiki - in online graduate education. Journal of Information Systems Education, 21(3), 313-321.

Scutter, S., Stupans, I., Sawyer, T., \& King, S. (2010). How do students use podcasts to support learning? Australasian Journal of Educational Technology, 26(2), 180-191.

Shelma, A., \& Nachmias, R. (2007). Current State of Web-Supported Courses at Tel-Aviv University. International Journal on E-Learning, 6(2), 235-246.

Shim, J.P., Shropshire, J., Park, S., Harris, H., \& Campbell, N. (2006). Perceived Value of Podcasting: Student Communication-Medium Preferences. Proceedings of the 12th Americas Conference on Information Systems. Acapulco, Mexico, 2186-2194.

Smaldino, S. E., Russel, J. D., Heinich, R., \& Molenda, M. (2005). Instructional Technology and Media for Learning. Upper Saddle River, NJ: Pearson Merrill Prentice Hall.

Taylor, L., \& Clark, S. (2010). Educational Design of Short, Audio-only Podcasts: the Teacher and Student experience. Australasian Journal of Educational Technology, 26(3), 386-399.

Temple, N. J., Kemp, W. C., \& Benson, W. A. (2006). Computer Technology and Student Preferences in a Nutrition Course. Open Learning, 21(1), 71-77. http://dx.doi.org/10.1080/02680510500472262

Vajoczki, S., Watt, S., Marquis, N., \& Holshausen, K. (2010). Podcasts: Are they an effective tool to enhance student learning? A case study from McMaster University, Hamilton Canada. Journal of Educational Multimedia and Hypermedia, 19(3), 349-362.

Venkatesh, V., Morris, M. G., Davis, G. B., \& Davis, F. D. (2003). User acceptance of information technology: Toward a unified view. MIS Quarterly, 27(3), 425-478.

\section{$(\mathrm{cc}) \mathrm{BY}$}

This work is licensed under a Creative Commons Attribution 3.0 License. 